\title{
Professor Kazuyuki Sasaki, MD: Clinician, Scientist, Leader in Cataract Research, and Friend
}

\author{
Otto Hockwin \\ Center of Ophthalmology, Rheinische Friedrich-Wilhelms-Universität Bonn, Germany; \\ Department of Ophthalmology, Kanazawa Medical University, Uchinada, \\ Ishikawa, Japan
}

With some delay we celebrate the 65th birthday of Kazuyuki Sasaki, MD Professor in and Chairman of the Department of Ophthalmology, Kanazawa Medical University (KMU), Uchinada, Ishikawa and his retirement as the Director of the Department of Ophthalmology. He still will be involved with the work of his old institution at the KMU, which he has headed since 1977.

His colleagues and coworkers were eager to find a special gift to conclude the celebrations which took place on March 25, 2001. Professor Nobuo Takahashi, MD, the new Chairman and Director of the Department of Ophthalmology at the KUM and Dr. Masami Kojima finally came to the conclusion that a collection of publications covering the wide field of Professor Sasaki's long-standing scientific interest in lens and cataract research would be an appropriate way of commemorating the almost 25 years Professor Sasaki has spent at the KMU. Dr. David H. Sliney and two of Professor Sasaki's Japanese colleagues together with the author of this article formed the Editorial Board responsible for the volume which has now been published.

First of all we want to thank the Publishing House S. Karger AG Basel, Switzerland and the Editor of Developments in Ophthalmology Prof. Dr. med. W. Behrens-Baumann, Magdeburg, Germany for agreeing to the publication of a volume containing articles dedicated to Professor Sasaki by coworkers and colleagues from all over the world.

Kazuyuki Sasaki was born in 1935 in Manchuria. He received his medical education between 1955 and 1961 at the School of Medicine, Tohoku University. 
He spent 2 years internship (1961/1962) at the Sendai National Hospital and returned for postgraduate study to the School of Medicine, Tohoku University (1962-1966). After this he became a member of the senior staff in the Department of Ophthalmology of his school and in 1969 was appointed as a lecturer, a position he held until he left for Kanazawa.

In the years 1973-1975 he was for 24 months an invited lecturer at the Eye Hospital and at the Institute of Experimental Ophthalmology at the University of Bonn, Germany, after having been awarded a fellowship by the Alexandervon-Humboldt-Stiftung. In Bonn he met the Professor Emeritus Hans Karl Müller, the former Director of the University Eye Hospital Bonn, who had studied cataract formation resulting from galactose diet in rats at the Charite Eye Hospital University of Berlin together with Sasaki's father, Professor Toichiro Sasaki, MD, in the years 1937/1938 [1].

Having returned from Germany, K. Sasaki worked as an Associate Professor at his home university. In 1977 he was appointed Professor and Chairman of the Department of Ophthalmology at Kanazawa Medical University, a position he has continued to hold until today. In the years 1992-1994 he served as Vice-Director of Kanazawa Medical University Hospital, and from 1999-2000 he was the Director of the Library of the KMU. He is a permanent invited professor in the China Medical University (since 1985), as well as the Harbin Medical College (since 1987) and the Tongji Medical University (since 1993). He continues to be active in all three positions and has been asked to remain in them even after his retirement here at the KMU.

$\mathrm{He}$ is one of the founding members of the Scheimpflug Club and was Head of the Japanese Society for Crystalline Lens Research Meetings until 2000. He also chaired the Japan Cooperative Cataract Research Group. He acted as councilor for the Society of Japanese Ophthalmology, the Japanese Society for Cataract Research, the Ophthalmological Optics Society of Japan, the Japanese Society for Cataract and Refractive Surgery, Japanese Society of Ocular Pharmacology, the Japanese Association for Ocular Infection and the Japanese Ocular Inflammation Society. In 2000 he was elected as a member of the Board of Directors of the International Society for Toxicology.

During his term at the KMU he acted several times as a local organizer of international meetings covering the subjects of the Scheimpflug Club (1986, $1989,1995)$ or the epidemiology of cataracts $(1986,1990)$ or research with respect to UV damage of the eye $(1994,1999)$. Participants at these meetings will never forget the great hospitality of Professor Sasaki and the great engagement of the members of his department to guarantee a well-organized event. He has also been one of the organizers of the many Hawaii meetings of the US CCRG and Japanese Chapter. In the last years his activity was more and more directed to involve the Korean and Chinese colleagues in research meetings. 
He is a leader in clinical and basic eye research in the Asian Continent and will hopefully continue to be so for many years to come.

His achievements as a clinical researcher and promoter, supervisor and patron of basic eye research cover a wide field. Most of his scientific articles have been published in the Japanese language. But over the years more and more English language articles have been accepted by the international journals which cover our field. A selection of 30 publications have been selected and demonstrate the variety of Professor Sasaki's contributions to our knowledge [2-31].

Professor Sasaki has always been able to recruit research associates from the young residents in his department and their collaboration has produced some remarkable results. Also the number of foreigners (coming from China, Indonesia, Germany, Bulgaria) who try to obtain fellowships to work in the laboratories of Professor Sasaki demonstrates the quality of his leadership and supervision. Moreover, he has initiated international cooperation (cataract epidemiology) with Indonesia, Singapore, Iceland and Australia and these projects are still running thanks to his efforts and enormous energy.

Whereas most ophthalmic surgeons do little more than remove the opacified lenses and replace them with intraocular lenses in patients with cataracts, Sasaki is one of the few clinicians who is also interested in the pathogenesis, risk factors and mechanisms that lead to cataracts and his contributions in the field of cataract epidemiology are fundamental for the present state of the art in cataract research.

It is to be hoped that his work will influence researchers worldwide and thus lead research in the fight against cataract blindness with new ways - other than only surgery - of preventing cataract development.

In conclusion, I would like to say a few words about our long-standing friendship. We first met during his stay at Bonn. At this time our institute was constructing a camera instrument which allowed slit image photographs to be taken according to Scheimpflug's principle (1994/1995). He was working at this time with fluorescein angiography with different dyes in animals. He was quick to recognize the value of the Scheimpflug method for research of the anterior eye segment. It was his personal input to find ways of manufacturing the camera that had been constructed in our laboratories. In his new position as Professor and Chairman at the KMU he cooperated with us during a 2-year test phase of the instrument and initiated technical improvements and discovered many clinical applications. His contributions to the image analyses were of great value when the method was introduced.

We have remained in very close contact during the ensuing years with visits to each other and we have been able to organize an exchange of coworkers for longer periods in order to focus on current local projects. Throughout the years we have had a full exchange of ideas and we have even planned future projects 
and mapped out the single steps between our institutions. When I retired in 1990 as Director of the Institute of Experimental Ophthalmology at the University of Bonn the Department of Ophthalmology of the KMU became my second scientific homeland. I am today very happy about several joint research projects which we have been able to successfully pursue within the last 10 years.

I wish to thank the organizers of this celebration party and the coeditors of this volume for the opportunity to express my admiration of Kazuyuki Sasaki as a clinician, as a scientist, as a leader in ophthalmology at the end of the 20th century. I also attach great value to our friendship. I wish him, his wife Mrs. Kofuji Sasaki and his family many more healthy and fruitful years.

\section{References}

1 Sasaki T: Untersuchungen der Linse, des Blutes und des Kammerwassers von Ratten bei Galaktoseverfütterung. Von Graefes Arch Ophthalmol 1938;138:351-387.

2 Sasaki K, Lemmingson W, Baurmann H, Chioralia G, Hendrickson P: Observation of injected fluorescein diffusion after laser treatment of cat fundi. Albrecht Von Graefes Arch Klin Exp Ophthalmol 1976;198:7-16.

3 Sasaki K, Yamashita Y, Maekawa T, Adachi T: Treatment of retinopathy of prematurity in active stage by cryocautery. Jpn J Ophthalmol 1976;20:384-395.

4 Dragomirescu V, Hockwin O, Koch H-R, Sasaki K: Development of a new equipment for rotating slit image photography according to Scheimpflug's principle. Interdiscipl Top Gerontol. Basel, Karger, 1978, vol 13, pp 1-13.

5 Sasaki K: A new approach to crystalline lens documentation. J Ophthalmic Photogr 1986;9: 112-115.

6 Sasaki K, Hiiragi M, Sakamoto Y: Changes of crystalline lens transparency with ageing in healthy individuals. Lens Res 1986;3:239-251.

7 Sasaki K, Sakamoto Y, Shibata T, Nakaizumi H, Emori Y: Measurement of postoperative intraocular lens tilting and decentration using Scheimpflug images. J Cataract Refract Surg 1989;5: 454-457.

8 Fukuda M, Sasaki K: Intraocular dynamic mode differences of new quinolone antibacterial agents between pigmented and albino rabbit eyes. Lens Eye Toxicity Res 1989;6:339-351.

9 Sasaki K, Shibata T, Obazawa H, Fujiwara T, Kogure F, Obara Y, Itoi M, Katou K, Akiyama K, Okuyama S: Classification system for cataracts. Application by the Japanese Cooperative Cataract Epidemiology Study Group. Ophthalmic Res 1990;22:46-50.

10 Sasaki K, Sakamoto Y, Shibata T, Emori Y: The multi-purpose camera: A new anterior eye segment analysis system. Ophthalmic Res 1990;22:3-8.

11 Fukuda M, Sasaki K: Changes in the antibacterial activity of melanin-bound drugs. Ophthalmic Res 1990;22:123-127.

12 Sasaki K, Fujisawa K, Sakamoto Y: Quantitative evaluation of nuclear cataract using image analysis. Ophthalmic Res 1992;24:26-31.

13 Kojima M, Hockwin O, Sasaki K: A new approach to drug penetration study. Lens Eye Toxicity Res 1992;9:547-558.

14 Sakamoto Y, Sasaki K, Kojima M: Analysis of crystalline lens coloration using a black and white charge-coupled device camera. German J Ophthalmol 1994;3:58-60.

15 Malik A, Kojima M, Sasaki K: Morphological and biochemical changes in lenses of guinea pigs after vitamin-C-deficient diet and UV-B radiation. Ophthalmic Res 1995;27:189-196. 
16 Nishimoto K, Sasaki K: In vivo light scattering intensity in the lens versus in vivo spectral transmission in the nuclear region. Ophthalmic Res 1995;27:1-11.

17 Sasaki K, Kojima M: Population based cataract epidemiological surveys utilizing photodocumentation system. Doc Ophthalmol 1995;88:277-283.

18 Kojima M, Shui YB, Sasaki K: Topographic distribution of prednisolone in the lens after organ culture. Ophthalmic Res 1995;27:25-33.

19 Sakamoto Y, Sasaki K: Computed tomographic images and three-dimensional expression of crystalline lens findings from multiple slices of Scheimpflug slit images. Ophthalmic Res 1995; 27:94-99.

20 Sasaki K: Scheimpflug photography as a tool for anterior eye segment biometry. Opt Eng 1995; 34:758-764.

21 Kojima M, Shui YB, Murano H, Sasaki K: Inhibition of steroid-induced cataract in rat eyes by administration of vitamin-E ophthalmic solution. Ophthalmic Res 1996;28:64-71.

22 Shui YB, Kojima M, Sasaki K: A new steroid-induced cataract model in the rat: Long-term prednisolone applications with a minimum of X-irradiation. Ophthalmic Res 1996;28:92-101.

23 Sasaki K: Epidemiology - Search for risk factors of cataract formation. Nova Acta Leopoldina NF 1997;299:25-36.

24 Sakamoto Y, Kojima M, Emori Y, Sasaki K: Ultraviolet dosimetry utilizing a mannequin model. Dev Ophthalmol 1997;27:50-55.

25 Sasaki K, Kojima M, Nakaizumi H, Kitagawa K, Yamada Y, Ishizaki H: Early lens changes seen in patients with atopic dermatitis applying image analysis processing of Scheimpflug and specular microscopic images. Ophthalmologica 1998;212:88-94.

26 Sasaki H, Hockwin O, Kasuga T, Nagai K, Sakamoto Y, Sasaki K: An index for human lens transparency related to age and lens layer: Comparison between normal volunteers and diabetic patients with still clear lenses. Ophthalmic Res 1999;31:93-103.

27 Sasaki H, Jonasson F, Kojima M, Katoh N, Ono M, Takahashi N, Sasaki K: The Reykjavik eye study - Prevalence of lens opacification with reference to identical Japanese studies. Ophthalmologica 2000;214:412-420.

28 Sasaki H, Shui YB, Kojima M, Chew SJ, Ono M, Katoh N, Cheng HM, Takahashi N, Sasaki K: Characteristics of cataracts in the Chinese Singaporean. J Epidemiol 2001;11:16-23.

29 Sasaki K, Hockwin O, Sakamoto Y, Sasaki H, Kojima M: High hurdle of clinical trials to demonstrate efficacy of anticataractogenic drugs. Ophthalmologica 2000;214:390-398.

30 Nagata M, Kojima M, Sasaki K: Effect of vitamin E eye drops on naphthalene-induced cataract in rats. J Ocul Pharmacol Ther 2000;15:345-350.

31 Shui YB, Sasaki H, Pan JH, Hata I, Kojima M, Yamada Y, Hirai K, Takahashi N, Sasaki K: Morphological observation on cell death and phagocytosis induced by ultraviolet irradiation in a cultured human lens epithelial cell line. Exp Eye Res 2000;71:609-618.

Prof. Dr. Dr. h.c. Otto Hockwin, Tulpenweg 4, D-53757 Sankt Augustin (Germany)

Tel. +492241 203048, Fax +492241 27525, E-Mail otto.hockwin@t-online.de 